Over $45 \%$ of the applicants surveyed had relatives who were either dentists or doctors.

- A total of $43 \%$ came from comprehensive schools. This compares to over $86 \%$ of the population of England who attend comprehensive schools.

- Dentistry had not been selected as the first choice career for $9.2 \%$. Over half of this group had chosen medicine.

- Careers advice should be given early and directed towards the target audience.

- The representation of ethnic minorities is rising in dentistry, but it is important to work alongside the widening participation agenda to broaden the social and cultural intake.

\title{
The future of the profession - a survey of dental school applicants
}

\author{
F. M. J. Stewart, ${ }^{1}$ J. R. Drummond, ${ }^{2}$ L. Carson ${ }^{3}$ and G. Hoad Reddick ${ }^{4}$
}

Purpose To gather background information about applicants to the dental undergraduate course, and ascertain the factors involved in their decision to study dentistry.

Method Applicants attending for interview at Dundee and Manchester Dental Schools completed anonymous questionnaires. The useable response rate was $94 \%(n=436)$.

Results There were equal numbers of male and female applicants to the two schools as a whole. Although there was a much broader ethnic mix in the applicants to Manchester, the overall proportion of minority ethnic groups was considerably greater than in the UK population as a whole. Seventy-five per cent came from professional backgrounds, although marked differences were apparent between ethnic groups. A quarter had family relations who were dentists, and 30\% were related to doctors. Over half (53\%) decided to apply within the last year, with popular motivating factors including a general interest in dentistry, a desire to help people and to work with their hands. Dentistry was the first choice of career of $89 \%$, with medicine the most popular alternative.

Conclusion Valuable information was gathered from these prospective dental students regarding their backgrounds and the decision process involved in their career selection. This will prove beneficial when developing the recruitment process and allow appropriate tailoring to the target audience.

\section{BACKGROUND}

It is widely accepted that there is currently a shortage of working dentists in the UK. This undersupply was not helped by the closure of two UK dental schools and a $20 \%$ reduction in student intake following the report of the University Grants Committee in 1988. A number of additional factors have contributed to the present situation with regard to the workforce.

${ }^{1}$ Lecturer in Restorative Dentistry, ${ }^{2}$ Senior Lecturer in Restorative Dentistry, Dundee Dental School, Dundee University, ${ }^{3}$ Lecturer in Psychology, Division of Psychology, School of Social and Health Sciences, University of Abertay, ${ }^{4}$ Senior Lecturer in Dental Education (retired), Turner Dental School, University of Manchester Correspondence to: F. M. J. Stewart, Dundee Dental School, Dundee University, Dundee. DD14HN

Email:f.m.j.stewart@dundee.ac.uk

\section{Refereed Paper}

Received 4.03.03; Accepted 9.10.03

DOI: $10.1038 / \mathrm{sj}$. bdj.4811810

$\odot$ British Dental Journal 2004; 197: 569-573

\section{Student intake}

In 2002, 926 students, $60.6 \%$ of whom were female, gained entry to the dental undergraduate course at the 14 dental schools in the UK. ${ }^{1}$ The proportion of women entering the profession has been rising steadily from 11\% in 1962 when statistics were first officially broken down by gender, and reached 50\% in $1992 .^{2}$

\section{Traditional career paths}

Previous published research has shown that women follow a different work pattern to their male counterparts, and are more likely to take career breaks and work part time after they have children. It follows, therefore, that if more women enter the profession, the available workforce will reduce. ${ }^{3,4,5}$

\section{Student drop out}

Evidence has also shown that between 8\% and $17 \%$ of dental undergraduate students drop out prior to completing the course, approximately equating to the output of two dental schools each year. ${ }^{6}$ Similar statistics have been noted in Norway, where it has been found that $75 \%$ of students who drop out, do so because of a lack of motivation or interest in a career in dentistry. ${ }^{7}$

\section{Retirement}

This is the single most important cause of loss of workforce to the profession. A recent study in Scotland showed two thirds of GDPs intended to retire early, with half of this group planning to reduce their working hours prior to complete retirement. ${ }^{8}$

\section{Purpose and design of the survey}

Applicants to the dental undergraduate courses at Dundee and Manchester were asked to complete a questionnaire when they attended for interview in the spring of 


\section{EDUCATION}

Table 1 Gender and ethnic group for all respondents. Percentage as a proportion of respondents at each particular dental school (actual number)

\begin{tabular}{|c|c|c|c|c|c|c|}
\hline & Dundee & Manchester & & & & \\
\hline & Male & Female & Total & Male & Female & Total \\
\hline White & 36 (98) & 47 (128) & 83 (226) & 33.5 (55) & 20.7 (34) & $54.2(89)$ \\
\hline Pakistani & $2.2(6)$ & $1.1(3)$ & 3.3 (9) & $7.3(12)$ & $3(5)$ & $10.3(17)$ \\
\hline Indian & $2.9(8)$ & $1.8(5)$ & 4.7 (13) & $8.5(14)$ & 8.5 (14) & $17(28)$ \\
\hline Asian & $0.4(1)$ & $0.4(1)$ & $0.8(2)$ & $2.4(4)$ & $3.7(6)$ & $6.1(10)$ \\
\hline Arabic & $2.6(7)$ & $1.1(3)$ & 3.7 (10) & $0.6(1)$ & $0(0)$ & $0.6(1)$ \\
\hline Chinese & $0.4(1)$ & $0.4(1)$ & $0.8(2)$ & $0.6(1)$ & $1.2(2)$ & $1.8(3)$ \\
\hline Other & $1.5(4)$ & $1.8(5)$ & 3.3 (9) & $3(5)$ & $6.7(11)$ & 9.7 (16) \\
\hline Total & 46 (125) & 54 (146) & $100(271)$ & $55.9(92)$ & $43.8(72)$ & $100(164)$ \\
\hline
\end{tabular}
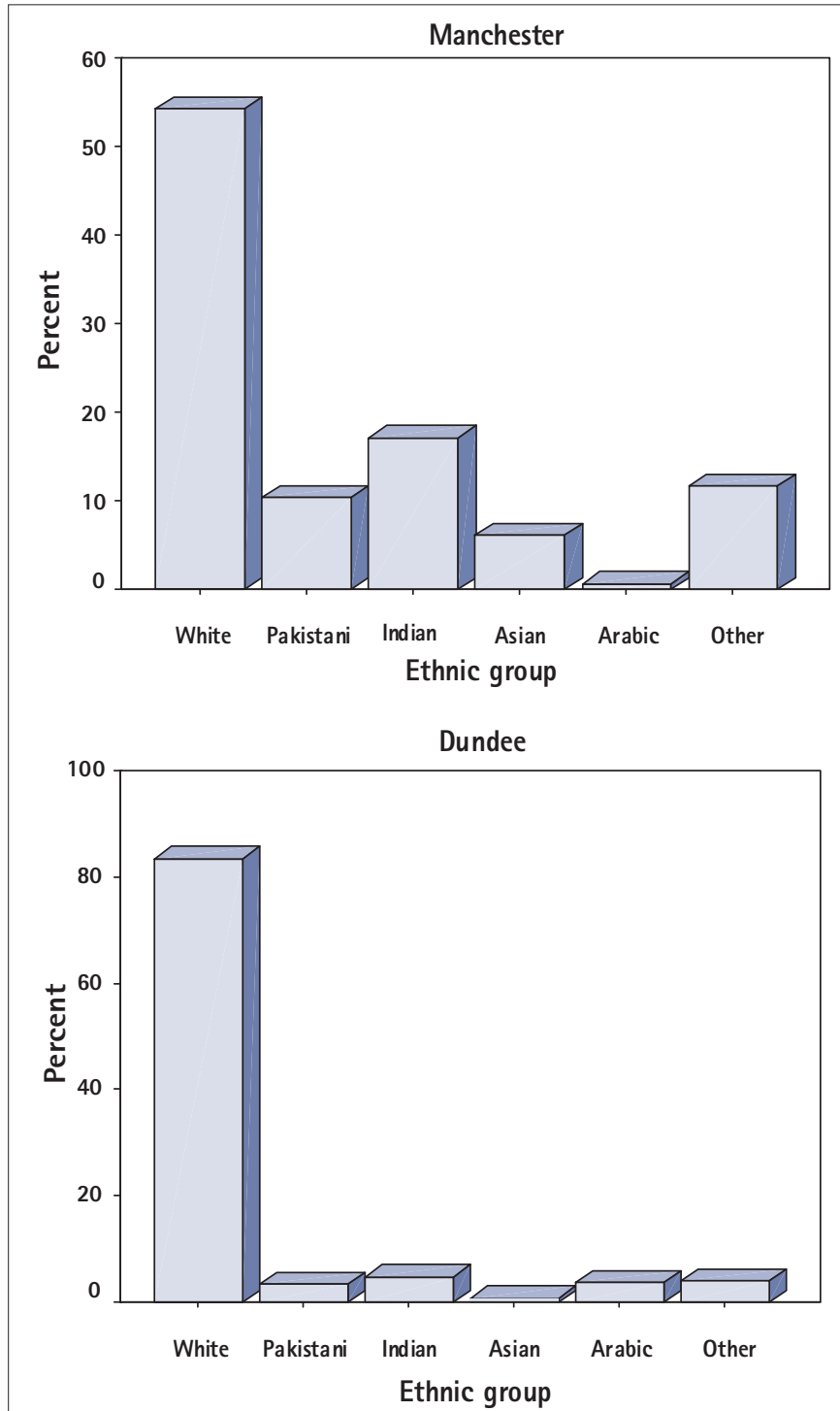

Fig. 1 Ethnic group distribution of applicants at Dundee and Manchester

Table 3 Incidence of dentist / doctor relations as percentage of each ethnic group. (actual)

\begin{tabular}{llccl}
\hline Ethnic group & Dentist relations & Doctor relations & Either dentist / doctor & None \\
\hline White & $20.5(63)$ & $22.8(70)$ & $35.5(109)$ & $64.5(198)$ \\
Pakistani & $35.5(9)$ & $65.4(17)$ & $76.1(20)$ & $23.1(6)$ \\
Indian & $46.3(19)$ & $58.5(24)$ & $75.6(31)$ & $24.4(10)$ \\
Asian & $58.3(7)$ & $33.3(4)$ & $66.7(8)$ & $33.3(4)$ \\
Other & $33.3(13)$ & $43.6(17)$ & $61.5(24)$ & $38.5(15)$
\end{tabular}

$\begin{aligned} & \text { Table } 2 \\
& \text { ethnic groups (percentages within each ethnic } \\
& \text { group) }\end{aligned}$
\begin{tabular}{lcc} 
grouss & Soconomic classification and \\
\hline Ethnic group & $\begin{array}{l}\text { Class } 1 \text { and } 2 \\
\text { (professional) }\end{array}$ & $\begin{array}{l}\text { Class } 3-8 \\
\text { (non-professional) }\end{array}$ \\
\hline White & $78.5(247)$ & $19.9(64)$ \\
Pakistani & $41.9(11)$ & $48.4(13)$ \\
Indian & $60.9(26)$ & $32.6(12)$ \\
Asian & $85.7(10)$ & $14.3(2)$ \\
Arabic & $71.4(9)$ & $7.1(1)$ \\
Other & $72.7(22)$ & $18.2(5)$
\end{tabular}

1998 and 1999, prior to commencing the course in October of those years. All participants were informed that the responses were anonymous, and would not be seen by any of the panel, nor have any influence over their subsequent interview. The study was designed to determine the factors that motivated the respondents to select a career in dentistry, as well as identify characteristics about their backgrounds. Prior to this study, research has concentrated either on students further into the undergraduate course, or post graduation. The decision to investigate school leavers was made in order to see whether family background or experience had an effect on future career plans before exposure to influences in dental school. A further aim was to collate the responses and anticipate future work patterns in the profession.

There was a useable response rate of 94\% (436) after disregarding papers that were largely incomplete or defaced.

Statistical analysis was carried out with SPSS version 10, using cross tabulations to compare responses from different groups.

\section{ANALYSIS OF RESPONSES \\ Background}

The gender and ethnic group analysis at both dental schools is shown in Table 1 . Overall there were equal numbers of male and female applicants, although there was a larger proportion of females at Dundee (54\%) than Manchester (44\%).

The wider ethnic mix of applicants to study at Manchester is shown in Figure 1.

Social classification was determined using the data collected regarding parental occupations and the National Statistics Socio-Economic Classification (NS-SEC) and is shown in Table 2. If at least one parent had a professional or managerial role, then they were cited as Class 1 or 2. The group as a whole showed $75 \%$ to be Class 1 or 2 and $22 \%$ from non professional backgrounds. Considerable variation was seen between the ethnic groups, with the Asian group having the highest proportion of applicants from Class 1 and 2 backgrounds $(86 \%)$ and the Pakistani group having the highest proportion from non professional backgrounds (48\%). No significant differences were observed between the sexes. 
A summary of the involvement of family members in dentistry or medicine is summarised in Table 3. A total of $25.4 \%$ had relations who were dentists and 30.3\% stated they had relations who were doctors.

The responses showed that more than twice the proportion (9.9\%) had a parent who was a doctor, compared to a dentist (4.1\%). There was little difference between the incidence of dentists and doctors for siblings (4.1\% dentists, 4.6\% doctors) and other relations (17.2\% dentists, $15.8 \%$ doctors).

Further examination revealed that $45.2 \%$ had relations who were either dentists or doctors, and 26.1\% had relations in both the medical and dental professions.

The majority (42.7\%) of the applicants had finished their secondary education at a comprehensive school. The proportions attending grammar $(22.7 \%)$ and private (23.6\%) schools were similar, while 6\% completed their secondary education at sixth form college.

\section{The choice of a career in dentistry}

Over half (53\%) of the respondents had been considering a career in dentistry for between one and three years, and the same proportion (53\%) took the decision to apply to the dental course within the preceding year.

Most applicants (92.4\%) had experience of work shadowing a dentist prior to applying to the course, with a mode period of 1-2 weeks $(41.5 \%)$. Comparison by ethnic group showed that more white students (95.9\%) than the other groups combined $(85 \%)$ had shadowed a qualified dentist. Gender differences were also apparent, with more work experience by females (95.4\%) than males (90.3\%).

Table 4 summarises the extent to which the applicants agreed with a number of statements regarding motivating factors involved in the decision to study dentistry. The ones which were rated as most important were that dentistry itself was interesting, a desire to help people and to work with their hands. When the applicants were given a free opportunity to state why they chose dentistry, 'to work with / meet people' was the most common response (20\%). Another recurring reason was 'an interest in sciences and the scientific nature of dentistry' (18\%).

Figure 2 shows the relationship between whether the applicants had a relative who was a dentist, and a member of their family recommending dentistry as a career. Since this association was statistically significant, it is possible to surmise from this response that the people who were already in the profession were willing to endorse a similar career for their relatives. (male: $\chi^{2}$ $=10.592, \mathrm{p}<0.005$, female: $\chi^{2}=11.410$, $\mathrm{p}<0.003$ ), Figure 2 .

Table 4. Attractions of dentistry as a career ranked by percentage of students selecting particular responses

\begin{tabular}{lccc}
\hline & Agree $(\mathrm{n})$ & Neither agree / disagree (n) & Disagree \\
\hline I find dentistry very interesting & $96.3(420)$ & $2.5(11)$ & $1.1(5)$ \\
I want to help people & $93.6(408)$ & $5(22)$ & $1.1(5)$ \\
I enjoy working with my hands & $93.1(406)$ & $5.5(24)$ & $1.4(6)$ \\
I want to work in healthcare & $78.7(343)$ & $19(83)$ & $2.3(10)$ \\
I want a secure job & $76.1(332)$ & $21.3(93)$ & $2.1(9)$ \\
Dentistry will enable me to work & $67.9(296)$ & $26.4(115)$ & $5(22)$ \\
in an independent way & & & $5(22)$ \\
The profession has a high status & $60.1(262)$ & $33.7(147)$ & $8(35)$ \\
I want a well paid job & $53(231)$ & $39(170)$ & $35.1(153)$ \\
A friend or relative recommended it & $25.2(110)$ & $39.7(173)$ &
\end{tabular}

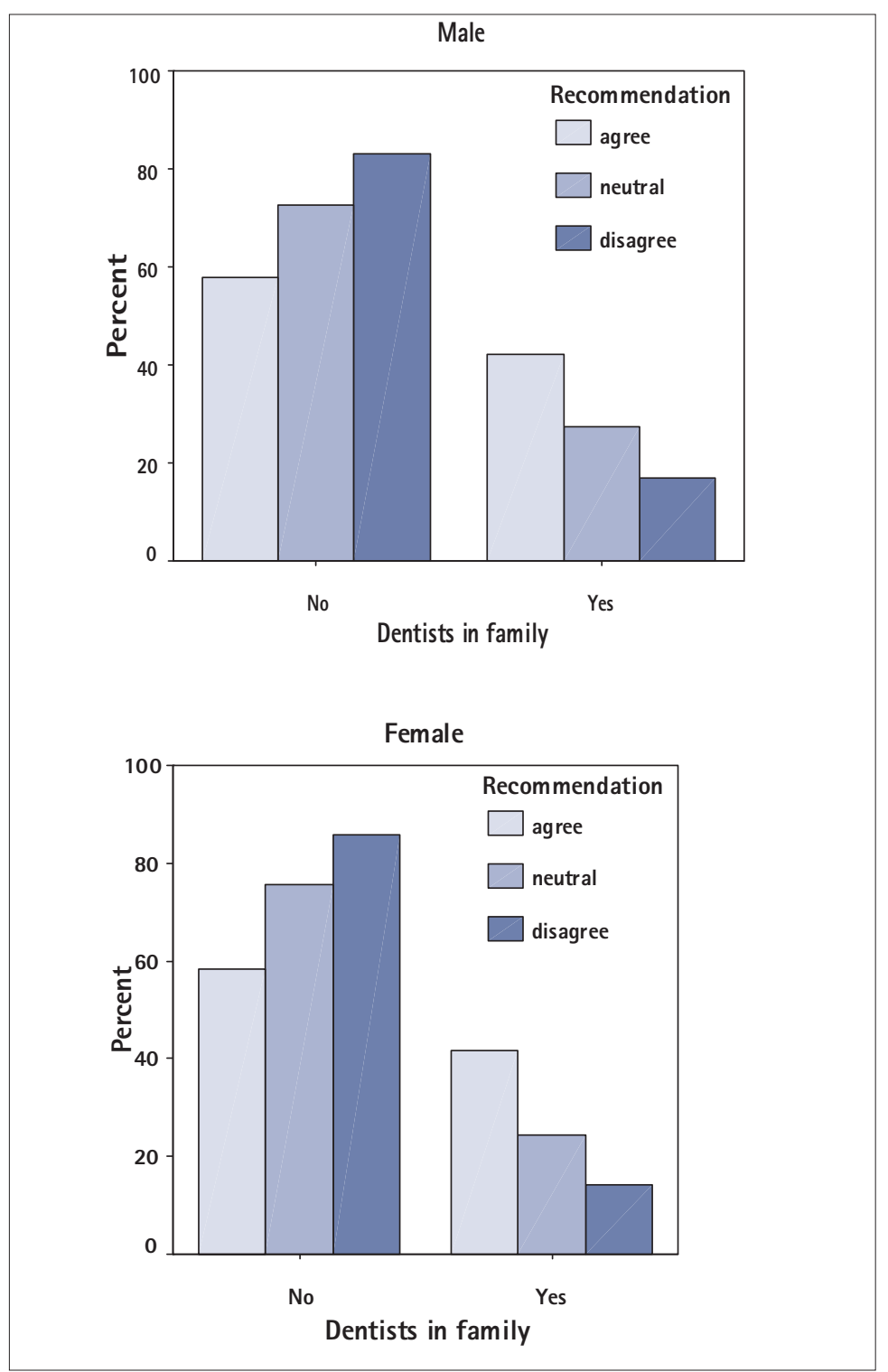

Fig. 2 The relationship between having a dentist relative and having dentistry recommended as a career

Dentistry was the first choice of career for $89.4 \%$ of the applicants. Of the $9.2 \%$ who stated it was not, 56\% selected medicine and $12.8 \%$ veterinary medicine.

Further examination of the figures showed almost twice the proportion of males (12.1\%) compared with females (6.5\%) did not select dentistry primarily.
Analysis of the males who did not choose dentistry first, demonstrated that $64 \%$ chose medicine and 16\% veterinary medicine.

Of the females in this category, although the most popular alternative career was medicine (42.9\%), a larger proportion of other options were chosen, including $21.4 \%$ 


\section{EDUCATION}

favouring nursing, 14.3\% both physiotherapy or nursing, and $7.1 \%$ veterinary medicine.

No significant differences were apparent between responses for ethnic groups.

\section{Problems to be encountered}

A total of $40.1 \%$ stated they were concerned about the level of debt associated with a five year undergraduate course, while $45.4 \%$ expressed no concern. Tuition fees were being introduced at the time of the survey, so this was a subject under a lot of scrutiny.

Financial problems were considered to be the main worry as undergraduates stated by $30.2 \%$, with a further $23.3 \%$ expressing concern about how they would cope with exams and the workload of the course.

Once qualified, 13.6\% were apprehensive about treating difficult or nervous patients, with a further $11.7 \%$ anxious about the stress and / or pressure involved in professional life.

Of the useable responses, $26.6 \%$ believed there were advantages to being male in dentistry, with $29.3 \%$ of these respondents giving reasons related to gender stereotyping or discrimination eg male dominated profession, dentists traditionally male, or discrimination. It was considered that having children would not affect males' careers in the same way as females' by $17.2 \%$, and a further $15.5 \%$ felt that males had the advantage of greater physical strength.

On the other hand, $34.8 \%$ of the group as a whole felt there were advantages to being female, with the most commonly recurring reason that females are more sympathetic / gentle / caring (38.1\%).

A further 29\% felt that women and children prefer to receive treatment from a female, an echo of the reason cited as a disadvantage of being male in a dental career.

Discrimination was the most quoted disadvantage (37.4\%) of being female in the dental profession.

\section{DISCUSSION}

This study was unusual in that data was collected from two centres with quite different demographic characteristics.

Dundee has a population of around 166,000 , of whom $98 \%$ are white. The minority ethnic group distribution is led by Pakistanis (36\%) followed by Indians (19\%).

Manchester, on the other hand, has over twice the population of Dundee $(392,000)$ and a much wider ethnic mix. ${ }^{11}$ Ethnic minority communities constitute approximately $18 \%$ of the population, a figure which is forecast to rise to over $20 \%$ by 2006.

There is no way of knowing where students' home residence is from the data col- lected in this study, but one can speculate that the broader ethnic range of applicants at Manchester may be attracted by the diverse cultural background of the population in the city.

Considering that numbers of applications to UK dental schools by minority ethnic groups are already greater than their relative proportion in the population and rising, ${ }^{9}$ the significance of monitoring inter-racial differences is of particular importance when forecasting the future workforce.

Interesting variation was apparent when examining socio-economic classification of the respondents. The determining factor for classification was parental occupation, and if at least one parent had a professional or managerial role they were cited as Class 1 or 2 (National Statistics Socio-economic Classification NS-SEC). ${ }^{11}$

Examination of the Pakistanis and Indians, the two groups who had the largest percentages with lower socio-economic backgrounds, showed that they had similar proportions of dentist relations to the other groups. Although no parents were dentists, they had a greater proportion of siblings and other relations who were in the profession. However, the same two ethnic groups did have parents who were doctors, and both were in the top three groups in relation to the quota of doctor relations overall. The Asian group had the highest proportion of parents who worked in professional or managerial roles ie Class 1 or 2, and also the greatest incidence of relations who were dentists. Conversely none of them had a parent or sibling who was a doctor, but one third had another relative who was.

It follows that for these ethnic groups there appears to be a trend for the present generation, the majority of whom were born and educated in the UK, to be higher academic achievers than their predecessors. It is therefore likely that the increased proportion of ethnic minorities in higher education in general, will continue to grow for some time to come.

It is interesting that almost half of the applicants to dental school had relations who were dentists or doctors, but as an example of lack of social inclusion, it is of some concern. In addition, 42.7\% of applicants came from comprehensive school backgrounds. This figure is markedly lower than the $86 \%$ of school leavers in England who had a comprehensive education. ${ }^{19}$ Figures such as these ought to fuel efforts to make information available about careers in dentistry to all potential school leavers, regardless of their background, and provide more opportunities for work experience in different fields of the profession.

\section{Career selection}

A study such as this gives a valuable insight into the reasons why students decide to enter the dental profession. This information can help to plan and tailor recruitment techniques, especially given the alteration of the gender balance within the profession. In addition, a reduction in overall applications to the undergraduate course has been seen during the last decade, although fluctuations have occurred from year to year, so it is essential to keep up momentum in the drive to attract suitable applicants for the course. ${ }^{10}$

The study allowed a comparison of responses from applicants to two dental schools in the United Kingdom. From these applications, Dundee accepts approximately 55 students each year, compared to around 65 at Manchester.

Common themes have emerged from studies investigating reasons for pursuing a dental career, with aims such as helping and working with people proving popular along with ease of employment, job security, the potential to earn a good income and an interest in dentistry. ${ }^{12-18}$ This study found similar motivational factors amongst the cohort, although financial reasons were cited as less important than in some previously published papers. Females tended to favour the statements relating to helping people and working in healthcare, as shown in studies in the USA. ${ }^{18}$ Recommendation by friends or family already in the profession appeared to influence the applicants least out a number of statements regarding attractions to dentistry. Nonetheless, a greater proportion of people with relations who were dentists felt this was an influence $\left(\chi^{2}=48.484, p<0.001\right)$. This trend was also seen in the group who had a relation who was a doctor, but to a lesser extent $\left(\chi^{2}=22.481\right)$. Another significant finding was that more males (64.2\%) than females $(57.7 \%)$ felt influenced by the perceived high status of dentistry $\left(\chi^{2}=12.603\right.$, $\mathrm{p}<0.05$ ).

Dentistry was not the first choice of university course for 9.2\% of the cohort, with most of this group preferring medicine. This was a similar proportion to a study 10 years ago. ${ }^{14}$ Without further evidence it is only possible to surmise that this group did not expect to gain the required grades for entry to medical school.

A consequence of this preference for a medical career may lead to a problem in recruitment to dentistry, since a shortage of doctors has lead to a rise in the intake to medical schools in the UK. In addition the existing gender imbalance in recruitment to dentistry may be tipped even further since a larger proportion of males expressed a preference for medicine than females. 


\section{CONCLUSION}

A number of conclusions can be drawn from the responses as a whole.

- Careers advice should be tailored differently for males and females since they are attracted to dentistry for slightly different reasons.

- Aim careers advice around three years ahead of leaving school, since this is when pupils are making decisions about career options.

- Work alongside the widening participation agenda to broaden the social and cultural intake of students.

- In spite of the present high application rate to dental schools, we must not be complacent because of the increase in medical school places.
1. UCAS annual report.2002.

2. Baldwin PJ, Dodd M, Rennie J S. Careers and patterns of work of Scottish dental graduates 1991 and 1994. Br Dent J 1998; 185: 238-243.

3. Seward M H, McEwen M E. The provision of dental care by women dentists in England and Wales in 1985: A ten year review. BrDent J 1987; 162: 50-51.

4. Matthews R W, Scully C. Working patterns of male and female dentists in the UK. Br DentJ 1994; 176: 463466.

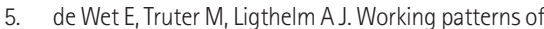
male and female dentists in South Africa. J Dent Assoc South Africa 1997; 52: 15-17.

6. Drummond J R, Duguid R. Student drop-out from UK dental schools. BrDent J 1997: 182: 347-349.

7. Jacobsen N. Causes and outcomes of discontinued dental studies. J Dent Educ 1994; 58: 771-774.

8. Russell E, Harrold T, Watson S. A Scottish survey of general and community dental practitioners 2000. The Toothousand project. Scottish Council for Postgraduate Medical and Dental Education. March 2001.

9. Bedi R, Gilthorpe M S. Ethnic and gender variations in university applicants to United Kingdom medical and dental schools. Br Dent J 2000; 189: 212-215.

10. Universities and Colleges Admissions Services- accepted applicants to dentistry 1996-01. http//:www.ucas.com

11. National Statistics Online. http//:www.statistics.gov.uk

12. Hallissey J, Hannigan A, Ray N. Reasons for choosing dentistry as a career - a survey of dental students attending a dental school in Ireland during 1998-99. EurJ DentEduc 2000; 4: 77-81.

13. Gietzelt D. Social profile of first-year dentistry students at the University of Sydney. Aus Dent J 1997; 42: 259-266.

14. Morris S. What kind of people want to become dentists? Br Dent J 1992; 173: 143-144.

15. Brand AA, Chikte U M E. Choosing dentistry as a career - part1: A comparison of student motives. J Dent Assoc South Africa 1992; 47: 469-473.

16. Vigild M, Schwarz E. Characteristics and study motivation of Danish dental students in a longitudinal perspective. Eur J DentEduc 2001; 5: 127-133.

17. Crossley M L, Mubarik A. A comparative investigation of dental and medical student's motivation towards career choice. Br Dent J 2002; 193: 471-473.

18. Scarbecz M, Ross J A. Gender differences in first-year dental students' motivation to attend dental school. $J$ DentEduc 2002; 66: 952-961.

19. The Office for National Statistics. Annual abstract of statistics, 2000 edition. London:Stationary Office. 